\title{
Small-scale mixing processes enhancing troposphere-to-stratosphere transport by pyro-cumulonimbus storms
}

\author{
G. Luderer ${ }^{1, *}$, J. Trentmann ${ }^{2}$, K. Hungershöfer ${ }^{3, * *}$, M. Herzog $^{4, * * *}$, M. Fromm ${ }^{5}$, and M. O. Andreae ${ }^{1}$ \\ ${ }^{1}$ Max Planck Institute for Chemistry, Dept. Biogeochemistry, Mainz, Germany \\ ${ }^{2}$ Institute for Atmospheric Physics, Johannes Gutenberg University Mainz, Mainz, Germany \\ ${ }^{3}$ Institute for Meteorology, University of Leipzig, Leipzig, Germany \\ ${ }^{4}$ NOAA GFDL, Princeton, New Jersey, USA \\ ${ }^{5}$ Naval Research Laboratory, Washington DC, USA, \\ * now at: Potsdam Institute for Climate Impact Research, Potsdam, Germany \\ ** now at: LISA, CNRS/Univ. Paris 7\&12, Crétail, France \\ **** now at: Department of Geography, University of Cambridge, Cambridge, UK
}

Received: 5 July 2007 - Published in Atmos. Chem. Phys. Discuss.: 19 July 2007

Revised: 19 November 2007 - Accepted: 19 November 2007 - Published: 6 December 2007

\begin{abstract}
Deep convection induced by large forest fires is an efficient mechanism for transport of aerosol particles and trace gases into the upper troposphere and lower stratosphere (UT/LS). For many pyro-cumulonimbus clouds (pyroCbs) as well as other cases of severe convection without fire forcing, radiometric observations of cloud tops in the thermal infrared (IR) reveal characteristic structures, featuring a region of relatively high brightness temperatures (warm center) surrounded by a U-shaped region of low brightness temperatures.

We performed a numerical simulation of a specific case study of pyroCb using a non-hydrostatic cloud resolving model with a two-moment cloud microphysics parameterization and a prognostic turbulence scheme. The model is able to reproduce the thermal IR structure as observed from satellite radiometry. Our findings establish a close link between the observed temperature pattern and small-scale mixing processes atop and downwind of the overshooting dome of the pyroCb. Such small-scale mixing processes are strongly enhanced by the formation and breaking of a stationary gravity wave induced by the overshoot. They are found to increase the stratospheric penetration of the smoke by up to almost $30 \mathrm{~K}$ and thus are of major significance for irreversible transport of forest fire smoke into the lower stratosphere.
\end{abstract}

Correspondence to: G. Luderer

(gunnar.luderer@pik-potsdam.de)

\section{Introduction}

Deep convection induced by large forest fires is a highly efficient mechanism for the vertical transport of gaseous and particulate fire emissions. In its most extreme form, this fireinduced convection is called pyro-Cumulonimbus (pyroCb), a phenomenon shown by both observational and modeling studies to result in direct injection of substantial amounts of smoke as high as into the lower stratosphere (Fromm and Servranckx, 2003; Fromm et al., 2005; Rosenfeld et al., 2007; Trentmann et al., 2006; Luderer et al., 2006). Due to a different chemical environment and the lack of washout processes, the lifetime of many tracers, such as aerosol particles and $\mathrm{NO}_{\mathrm{y}}$, is greater in the lower stratosphere than in the troposphere. The injection of biomass smoke therefore results in a substantial perturbation of the chemical composition and the radiative balance of the upper troposphere and lower stratosphere (UT/LS) region, with potentially far reaching consequences for atmospheric chemistry and even climate.

The Chisholm fire is one of the largest forest fires ever observed; it has been scientifically documented and thoroughly analysed in terms of its fire characteristics (ASRD, 2001; Fromm and Servranckx, 2003) as well as its atmospheric impact (Fromm and Servranckx, 2003; Trentmann et al., 2006; Luderer et al., 2006; Rosenfeld et al., 2007). Here, it serves as a case study for the assessment of the structure of overshooting cloud tops.

This study links two important aspects of intense deep convection: The occurrence of characteristic cloud top temperature patterns that are regularly associated with pyroCbs and other intense thunderstorms (cold $\mathrm{U}$ with an enclosed

Published by Copernicus Publications on behalf of the European Geosciences Union. 
warm center, see below), and the role of small-scale mixing processes at the cloud top in troposphere-to-stratosphere transport (TST).

Understanding and quantification of TST from midlatitude deep convection is not only important for pyroCbs, but also for intense regular thunderstorms. Even though mid-latitude deep convection accounts for only a small fraction of the air masses in the lowermost extra-tropical stratosphere (Holton et al., 1995), this process is very important for the budgets of many trace species in the lower stratosphere, most notably water vapor as well as some short-lived species (Mullendore et al., 2005). This is due to the rapid and direct transport from the planetary boundary layer, where most tracers have their sources. Several studies, e.g., Fischer et al. (2003), Ray et al. (2004), Hanisco et al. (2007) and Pittman et al. (2007), report direct observational evidence for the influence of water vapor and tracers into the lower stratosphere due to deep convection at high- and mid-latitudes. Numerical studies using cloud resolving models have investigated the characteristics of TST induced by deep convection. Wang $(2003,2007)$ identified gravity wave formation and breaking atop convective thunderstorm clouds as an important process for the injection of moisture plumes into the lower stratosphere. Lane et al. (2003) and Lane and Sharman (2006) found that the breakdown of gravity waves generated by thunderstorms is an important source of turbulence above the cloud and at tropopause level. Mullendore et al. (2005) assessed the vertical transport of idealized passive tracers by deep convection and found that, in addition to latent heating, mixing processes contribute significantly to potential temperature increases necessary for irreversible TST.

When observed from space, many pyroCbs, as well as intense regular thunderstorm clouds, feature a distinct cloud top temperature pattern. Due to its structure with a warm center surrounded by a U-shaped cold region, this feature will hereafter be referred to as the "cold U/warm center". Other studies refer to to this structure as enhanced-U or enhancedV structures (e.g., Wang et al., 2002b).

Typically, cold U brightness temperatures are lower than the tropopause minimum, while the temperatures in the warm center are higher than the temperatures of ambient air at the cloud top altitude. Observations of such thermal structures have been reported repeatedly in the literature (e.g., Heymsfield et al., 1983; Heymsfield and Blackmer, Jr, 1988; Levizzani and Setvák, 1996; Setvák et al., 2007; Rosenfeld et al., 2007).

Most of these studies agree that the cold $\mathrm{U}$ region is due to air masses that have cooled while ascending adiabatically beyond their level of neutral buoyancy and become exposed to the view of the satellite radiometer (e.g., Heymsfield and Blackmer, Jr, 1988; Rosenfeld et al., 2007). There is, however, substantial uncertainty about the cause of the warm center. In a recent study based on analysis of brightness temperatures at various wavelengths, Setvák et al. (2007) found that, for some storms, moisture plumes above the anvil level reach equilibrium with high stratospheric temperatures and mask the colder temperatures of the underlying cloud tops, thus giving rise to the observed warm center. Other studies suggested effects related to variations in radiative properties of cloud hydrometeors at the cloud top, with optically less opaque hydrometeors in the center allowing IR radiometers to see further down to a lower, hence warmer level of effective emission (Heymsfield et al., 1983). In this paper, we will demonstrate that both observations and simulations suggest that neither moisture masking nor effects related to the hydrometeors' radiative properties were relevant in our case study. The analysis of Rosenfeld et al. (2007) showed that the emissivity in the core is close to unity and does not show any inferred change of particle size in the warm center. Based on these observational results, and the simulation of the Chisholm pyroCb presented here, we infer that the warm center originated from subsidence and mixing of stratospheric air masses induced by gravity wave activity. This explanation is in good agreement with those proposed in earlier studies by Adler and Mack (1986) and Schlesinger (1984).

This paper is structured as follows: In the next section, observations of the Chisholm pyroCb are presented. In Sect. 3, the Active Tracer High Resolution Atmospheric Model (ATHAM) and the model setup used for this study are described. Section 4 presents an analysis of the cloud top structure based on the model results. Discussions and conclusions are presented in Sect. 5.

\section{Observations}

The Chisholm fire serves as a case study for this paper. In terms of its atmospheric impacts, the Chisholm fire is the largest boreal forest fire ever to be scientifically documented. Its fire characteristics were thoroughly documented by the Alberta Sustainable Resource Development agency. According to the post-burn assessment presented in ASRD (2001), the Chisholm Fire burned an area of 50000 ha in the time of its most intensive activity between 1700 and 2400 local time on 28 May 2001 alone. The fire intensity was up to $239000 \mathrm{~kW} \mathrm{~m}^{-1}$ (Trentmann et al., 2006; ASRD, 2001). The severe intensification of the fire-induced convection was observed to coincide with the passage of a synoptic cold front. As documented by numerous satellite and ground based observations, it injected substantial amounts of smoke into the lower stratosphere, which persisted for several months and resulted in a significant enhancement of the lower stratospheric aerosol loading on a hemispheric scale (Fromm and Servranckx, 2003, Fromm et al., 2007a ${ }^{1}$, Fromm et al.,

\footnotetext{
${ }^{1}$ Fromm, M., O. Torres, D. Diner et al., The stratospheric impact of the Chisholm Pyro-Cumulonimbus eruption: nadir satellite perspective, J. Geophys. Res., submitted, 2007a.
} 


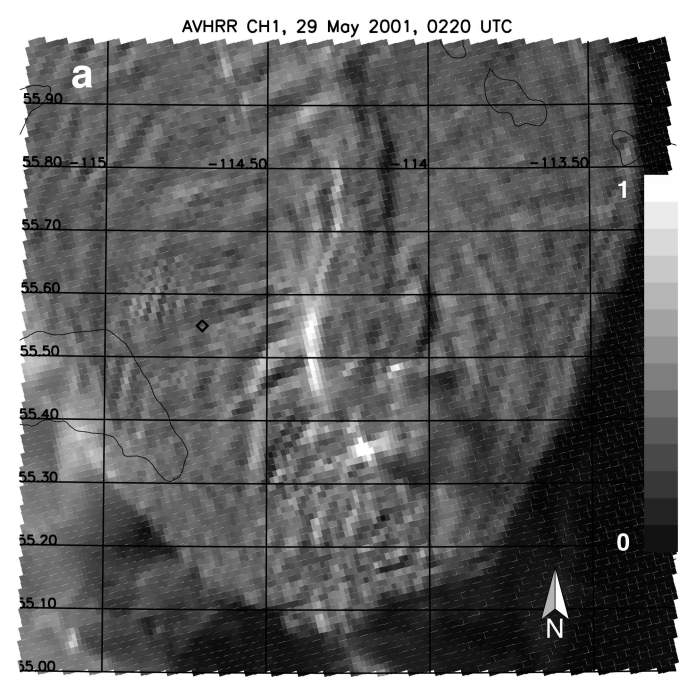

(a) $0.65 \mu \mathrm{m}$ reflectance

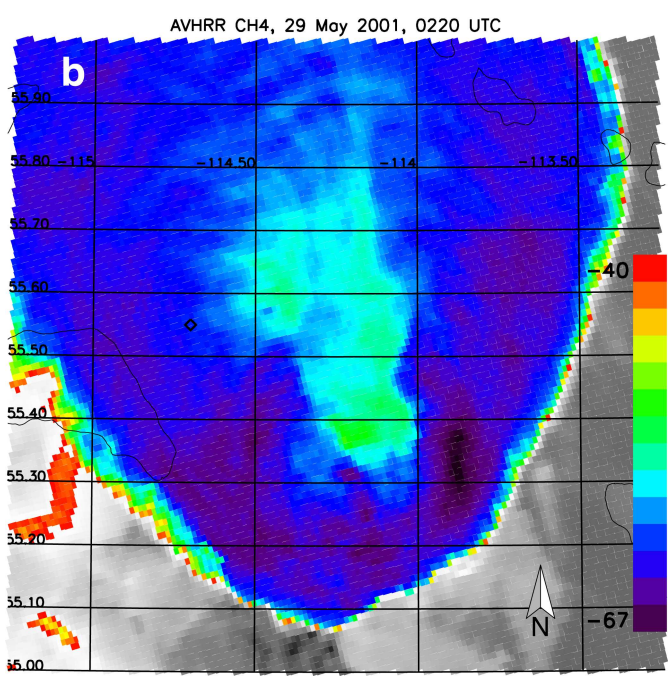

(b) $10.8 \mu \mathrm{m}$ brightness temperature

Fig. 1. Images from a NOAA AVHRR overpass during the mature phase of pyroCb convection. Reflectance in the visible $0.65 \mu \mathrm{m}$ channel is depicted in (a), brightness temperatures measured by the $10.8 \mu \mathrm{m}$ thermal IR channel are shown in (b). Reproduced from Rosenfeld et al. (2007).

$2007 b^{2}$ ). Rosenfeld et al. (2007) analyzed the structure, precipitation and lightning activity of the pyroCb based on satellite and RADAR data and found that the convection reached an altitude of about $13.5 \mathrm{~km}$. In an earlier modeling study, Trentmann et al. (2006) and Luderer et al. (2006) reproduced the observed structure of the Chisholm pyroCb, and assessed its sensitivity to fire activity and meteorological background conditions. It was found that the main driving forces for the vertical development of the convection and subsequent TST of smoke were the release of sensible heat from the fire and the background meteorological conditions, while the release of latent heat in the form of water vapor and the presence of aerosol particles acting as cloud condensation nuclei was of much lesser importance.

Not only the stratospheric aerosol plume produced by the Chisholm fire, but also the pyroCb convection itself was well captured by satellite observations (Fromm and Servranckx, 2003; Rosenfeld et al., 2007). Fortuitously, a NOAA Advanced Very High Resolution Radiometer (AVHRR) overpass occurred at 0220 UTC during the mature phase of the pyroCb convection. The anvil of the pyroCb is clearly visible in both the $0.65 \mu \mathrm{m}$ channel (Fig. 1a) and the thermal IR at $10.8 \mu \mathrm{m}$ (Fig. 1b).

The fire was located between approximately $55.0^{\circ} \mathrm{N}$ and $55.2^{\circ} \mathrm{N}$ at $114.3^{\circ} \mathrm{W}$, below the southern edge of the pyroCb anvil. Due to strong southerly winds associated with the passing cold front, the convection cell was tilted to the north and the anvil spread to northward directions. The areas of

\footnotetext{
${ }^{2}$ Fromm, M., E. Shettle, K.H. Fricke et al., The stratospheric impact of the Chisholm Pyro-Cumulonimbus eruption: vertical profile perspective, J. Geophys. Res., submitted, 2007b.
}

maximum reflectance and the shadows cast in the $0.65 \mu \mathrm{m}$ channel give a good indication of the location of the overshooting dome.

The cloud top temperatures of the pyroCb are much lower than those of the surrounding clouds that were not affected by the fire, showing that the fire induced convection reached much higher than ambient convection. As is the case for a number of other pyroCbs, the Chisholm pyroCb features a distinct pattern when observed from space with a thermal IR radiometer. While most of the anvil region is characterized by brightness temperatures of about $-61{ }^{\circ} \mathrm{C}$ to $-59^{\circ} \mathrm{C}$, corresponding to the tropopause cold point temperature level, a region with brightness temperatures that exceed those in the other parts of the anvil by $5-10 \mathrm{~K}$ is evident at the center of the pyroCb's top. This warm center structure is located above and downwind of the overshooting dome. In the upwind direction, the warm center is surrounded by an arch-shaped area of very cold temperatures. The background temperature profile at the time and location of the pyroCb convection was obtained from the radiosonde observations recorded at 00:00 UTC at Edmonton (Fig. 2), at about $200 \mathrm{~km}$ distance and shortly before the time of the convective blow-up of the pyroCb. The cloud top temperature structure is very remarkable since the coldest temperature of $-66^{\circ} \mathrm{C}$ is much colder than the tropopause cold point. Conversely, the warmest areas are warmer than $-52^{\circ} \mathrm{C}$. According to this sounding, temperatures were $-53.7^{\circ} \mathrm{C}$ or lower throughout the lower stratosphere. The observed temperature maximum can therefore not be explained by the overshooting into warm areas of the lower stratosphere alone. 

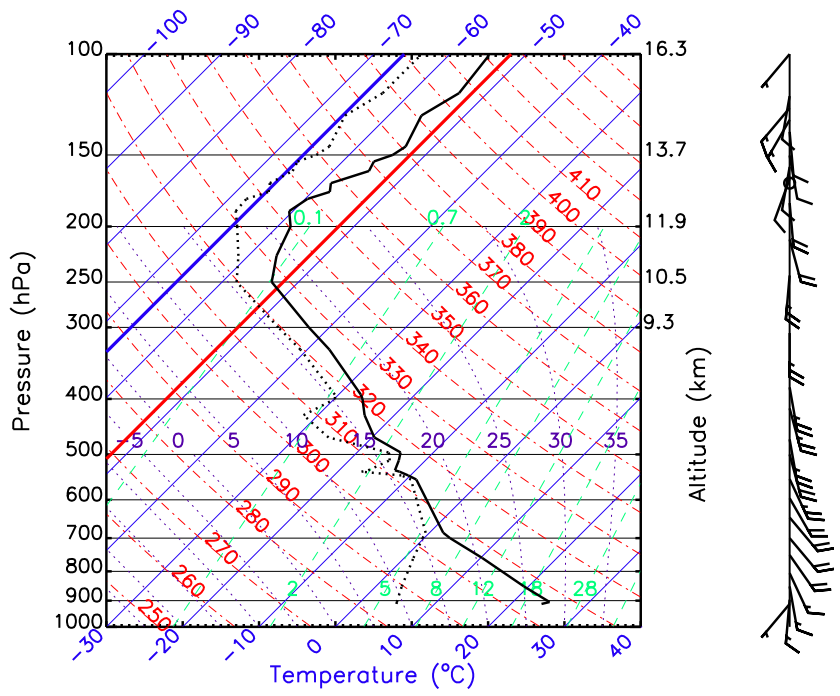

Fig. 2. Skew-T diagram depicting vertical profiles of temperature (solid line) and dew point temperature (dotted line) measured at Edmonton at 00:00 UTC. The thick red and blue isotherms indicate the maximum and minimum cloud top brightness temperatures as measured by the AVHRR. These deviate substantially from background tropopause temperatures. This sounding was also used for the initialization of the background meteorology in the model simulations. The arrows indicate the wind profile, with every full barb corresponding to $10 \mathrm{~m} \mathrm{~s}^{-1}$.

According to Inoue (1987), the actual cloud top temperature nearly equals the cloud top thermal temperature if the difference between the brightness temperatures recorded at $10.8 \mu \mathrm{m}$ and $12.0 \mu \mathrm{m}$ is within a fraction of a degree. Since the brightness temperature difference is near zero throughout the center of the Chisholm pyroCb's cloud top (Rosenfeld et al., 2007), we conclude that the observed brightness temperature pattern is representative of the actual temperature structure at the cloud top.

The cold U/warm center structure of the Chisholm pyroCb was also captured by the Defense Meteorological Satellite Program (Rene Servranckx, personal communication, 2005) and shows up as a persistent feature in the GOES geostationary satellite imagery (Fromm et al., 2007a). Similar cloud top brightness temperature patterns were also observed for other pyroCbs (Fromm et al., 2005) as well as regular thunderstorms (see Introduction), indicating that these are characteristic features of intense convection.

\section{The Active Tracer High Resolution Atmospheric Model (ATHAM)}

The numerical simulations presented here were performed with the Active Tracer High resolution Atmospheric Model (ATHAM), a non-hydrostatic cloud-resolving model origi- nally designed for the simulation of the extreme dynamical conditions present in plumes. In earlier studies, ATHAM was employed to investigate volcanic eruptions (e.g., Oberhuber et al., 1998; Herzog et al., 1998; Graf et al., 1999; Textor et al., 2003) and wildfire induced convection (Trentmann et al., 2002, 2006; Luderer et al., 2006).

The dynamical core of ATHAM is such that it fully accounts for the effects of all tracers such as hydrometeors, aerosols and gaseous components on heat capacity and density. The feedback of liquid and frozen cloud particles on the convection dynamics is therefore explicitly represented. The Euler equation is solved for a gas-particle mixture under the assumption of zero net fluxes between its constituents for momentum and heat. The volume mean momentum is conserved. The tracer advection is formulated in massconserving form.

For realistic simulation of entrainment of environmental air into the the plume, as well as detrainment and mixing of smoke at the cloud top, subgrid scale turbulence is parameterized using a modified turbulent kinetic energy (TKE) scheme. In this approach, TKE is a prognostic variable from which the horizontal and vertical turbulent exchange coefficients are derived (Herzog et al., 2003). Cloud microphysical processes are represented using a two-moment microphysical scheme (Textor et al., 2006a,b). There are four hydrometeor classes, namely, cloud droplets (small, liquid), rain drops (large, liquid), ice crystals (small, frozen), and graupel (large, frozen), for each of which mass concentrations and number densities are predicted. A total of 13 processes transferring water between the four hydrometeor classes and the vapor phase are considered.

The model setup is identical to that used in Trentmann et al. (2006) and Luderer et al. (2006). The fire forcing is assumed to be constant during the simulation and is represented as a rectangular front of $15000 \mathrm{~m}$ length and $500 \mathrm{~m}$ width. The model domain is $85 \mathrm{~km}$ in the direction along the fire front and $65 \mathrm{~km}$ across, with the upper boundary at $26 \mathrm{~km}$. The number of grid points used is $110 \times 85$ in the $\mathrm{x}$ and $y$-directions and 100 in the z-direction. We used a focusing grid with maximum resolution at the fire and its vicinity, where the gradients of tracer concentrations and temperature are largest. Towards the edges of the model domain, the grid spacing is larger. In the horizontal, the minimum grid spacing was set to $100 \mathrm{~m}$ perpendicular to the fire front and $500 \mathrm{~m}$ along the front. In the vertical, we used two regions of enhanced spatial resolution: the grid spacing was $50 \mathrm{~m}$ at the ground and, for more accurate simulation of troposphere-tostratosphere transport, $150 \mathrm{~m}$ at the tropopause. In the midtroposphere, the maximum vertical spacing was $300 \mathrm{~m}$.

The fire was assumed to consume $9 \mathrm{~kg} \mathrm{~m}^{-2}$ of fuel at a rate of spread of $1.5 \mathrm{~m} \mathrm{~s}^{-1}$. In this simulation run we assumed that $100 \%$ of the fire energy goes into the heating of the atmospheric layer over the fire, i.e., radiative losses were assumed to be zero. A fuel moisture value of $40 \%$ based on dry fuel mass was assumed. This yields a fire intensity, i.e., 


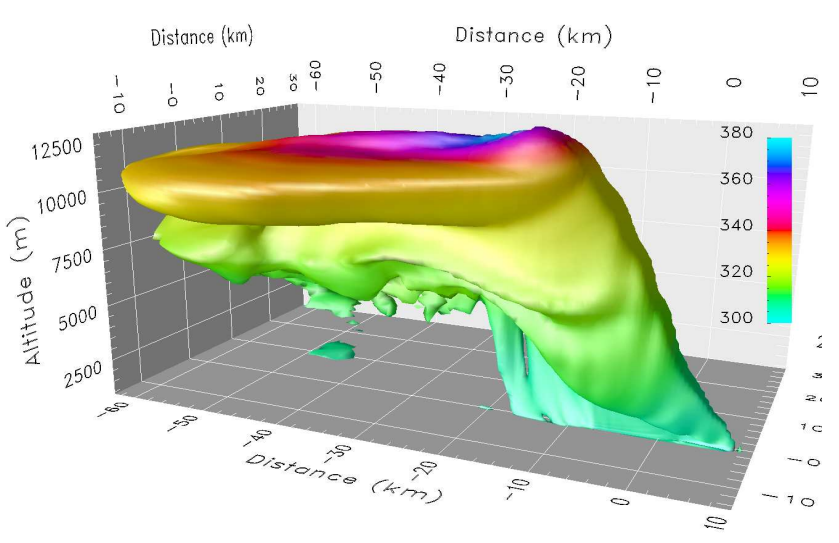

Fig. 3. Three-dimensional representation of the aerosol plume after 40 min simulation time. The $50 \mu \mathrm{g} \mathrm{m}^{-3}$ isosurface is color-coded with potential temperature in $\mathrm{K}$.

sensible heat release per unit fire front length, of $239 \times 10^{6} \mathrm{~W}$ $\mathrm{m}^{-1}$, and a moisture release of $12.2 \mathrm{~kg} \mathrm{~m}^{-1} \mathrm{~s}^{-1}$. For the aerosol emissions, we used an emission factor for total particulate matter (TPM) of $17.6 \mathrm{~g}_{\text {TPM }} \mathrm{kg}_{\text {fuel }}^{-1}$ (Andreae and Merlet, 2001) and assumed, for the particles, a volume mean diameter of $0.2 \mu \mathrm{m}$, which is consistent with Reid et al. (2005).

Background meteorology was adopted from radiosonde observations that were performed at Edmonton $\left(53.5^{\circ} \mathrm{N}\right.$, $114.1^{\circ} \mathrm{W}$ ), located about $200 \mathrm{~km}$ south of the fire location, at 00:00 UTC, shortly before the time of the blow-up (Fig. 2). This sounding is likely to closely match the meteorological background condition for the Chisholm pyroCb. Based on ECMWF reanalysis data, the dynamical tropopause (defined as the $2 \mathrm{PVU}$ potential vorticity level) was located at a potential temperature of $332 \mathrm{~K}$, corresponding to an altitude of $11.2 \mathrm{~km}$. Here, we opted to use the tropopause definition in terms of potential vorticity (PV) since it is most meaningful in terms of troposphere-stratosphere exchange at mid-latitudes. Since the PV isosurfaces become strongly disturbed during the active convection, we use the $332 \mathrm{~K}$ isentrope of potential temperature to calculate the TST from the model simulation.

Given the complicated three-dimensional structure of the pyroCb, the interaction of its dynamics with incident solar and thermal radiation from the fire are highly complex. Interactive broadband three-dimensional simulation of radiation is computationally much too expensive for simulations with cloud-resolving models such as ATHAM. Therefore, the following assumptions were made. Since most of the radiative energy from the fire is absorbed by the pyro-cloud, we assumed that the entire fire energy becomes available for the convection. This is consistent with the finding presented in Luderer et al. (2006) that the observed structure of the pyroCb can only be reproduced, if the radiative loss is small compared to the fire energy release. Moreover, effects of so-

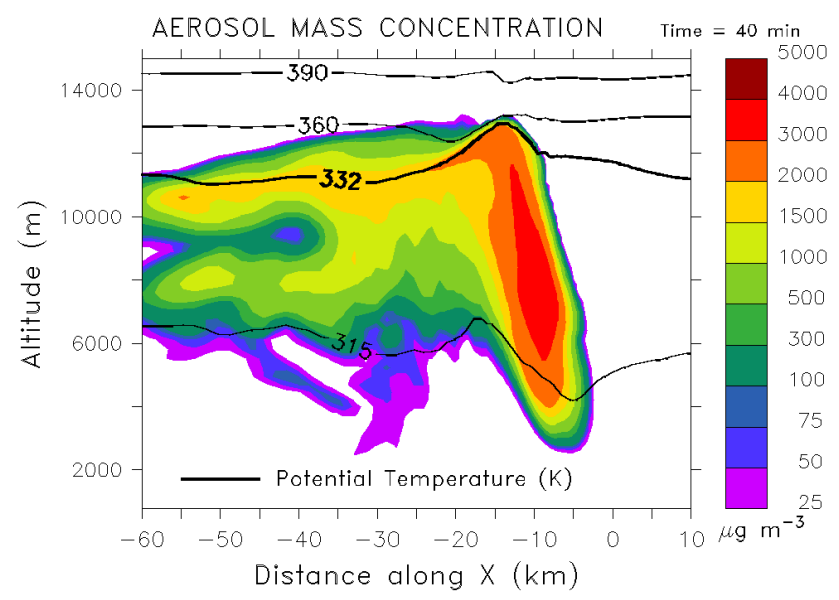

Fig. 4. Aerosol mass concentration along the $y=-5 \mathrm{~km}$ vertical cross section after $40 \mathrm{~min}$. Contour lines indicate potential temperature levels. The tropopause was located at $\theta=332 \mathrm{~K}$.

lar heating were assumed to be negligible. While it likely contributed substantially to the lofting of the stratospheric aerosol plume during the days after the Chisholm fire, solar heating is of low significance for the convective time scales of less than one hour and the large solar zenith angles during the convective phase considered here.

In order to compare the simulations with satellite observations of brightness temperature, an offline-simulation of the radiative properties of the pyroCb was performed using a one-dimensional, broadband, $\delta$-four-stream radiative transfer model (Fu and Liou, 1993; Hungershöfer, 2007). At each vertical column of the ATHAM grid, an independent-column calculation was performed. Up to an altitude of $26 \mathrm{~km}$, the vertical model layers were adopted from ATHAM. For the remaining part up to the top of the atmosphere at $80 \mathrm{~km}$, data for a standard mid-latitude summer atmosphere (Anderson et al., 1986) were applied. In total, this resulted in 129 horizontally homogenous layers with a thickness varying from $50 \mathrm{~m}$ near the surface to $10 \mathrm{~km}$ in the mesosphere. The brightness temperature was determined from the upwarddirected flux density at the top of the atmosphere for the wavelength band from $10.2 \mu \mathrm{m}$ to $12.5 \mu \mathrm{m}$. In this atmospheric window region, only the absorption of water vapor and the effect of the hydrometers had to be taken into account. To determine the optical properties of the four hydrometeor classes, pre-calculated values were scaled with the respective mass concentrations simulated with the ATHAM model. In the case of water droplets, a constant effective radius of $5 \mu \mathrm{m}$ was assumed. For ice crystals, a plate-like structure with an effective size of $25 \mu \mathrm{m}$ was applied, which roughly corresponds to an effective radius of about $10 \mu \mathrm{m}$ as obtained in the retrieval by Rosenfeld et al. (2007). Aerosol optical properties were considered as well, but their influence was found to be small in the wavelength region considered. 


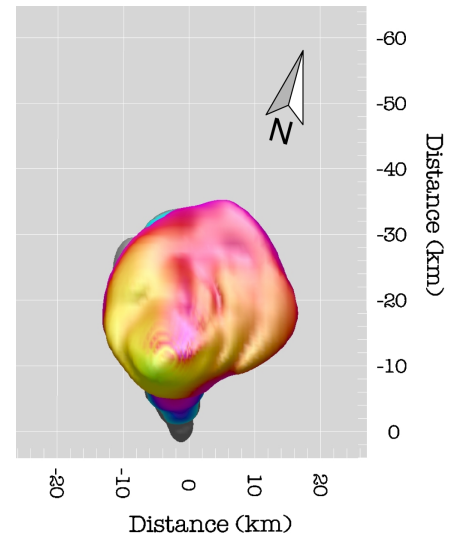

(a) $20 \mathrm{~min}$

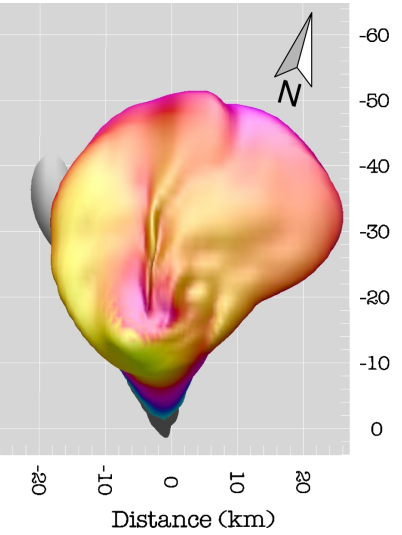

(b) $30 \mathrm{~min}$

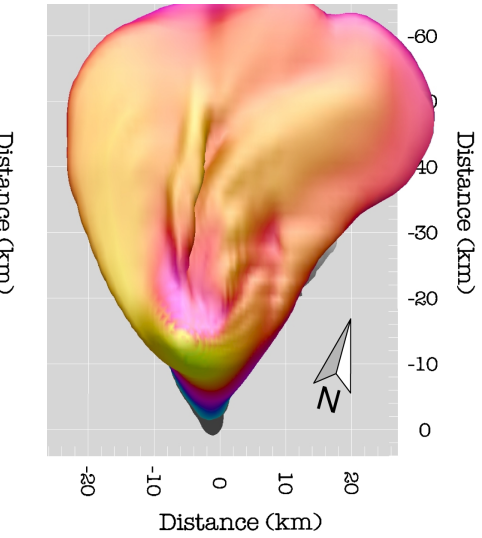

(c) $40 \mathrm{~min}$

Fig. 5. Cloud top temperatures in ${ }^{\circ} \mathrm{C}$ on the $0.5 \mathrm{~g} \mathrm{~kg}^{-1}$ hydrometeor concentration isosurface as simulated by ATHAM for three instances in time.

\section{Model results}

Two- and three-dimensional visualizations of the modeled smoke plume are provided in Figs. 3 and 4. Figure 3 depicts the $50 \mu \mathrm{g} \mathrm{m}^{-3}$ isosurface of aerosol mass concentration color coded with potential temperature $\theta$. In the coordinate frame used for the simulations, the $\mathrm{x}$-direction is aligned with the fire front orientation and is therefore rotated with respect to north by $165^{\circ}$. The overshooting cloud top is centered at $x=-15 \mathrm{~km}, y=-5 \mathrm{~km}$ and reaches to a maximum altitude of about $13,000 \mathrm{~m}$. At this altitude level, background winds were blowing from south-south-west, at an angle of about $25^{\circ}$ to the x-axis. In order to optimally capture the overshooting cloud top and its substructure, the vertical $2 \mathrm{~d}$ cross sections presented here were prepared along the $y=-5 \mathrm{~km}$ line. The vertical cross-section of the aerosol mass distribution depicted in Fig. 4 shows that the plume reached a peak altitude of $13 \mathrm{~km}$, well above the tropopause, which was located at $11.2 \mathrm{~km}$. The maximum potential temperature at the cloud top was approximately $360 \mathrm{~K}$.

4.1 Simulated radiative and thermal structure of the cloud top

Top views of the modeled smoke cloud at three different times are given in Fig. 5. The pyroCb is represented by the $0.5 \mathrm{~g} \mathrm{~kg}^{-1}$ hydrometeor concentration isosurface and has been color-coded with the temperature field on this isosurface, thus showing the "skin temperature" of the cloud top. Similar to the satellite observations, the thermal structure of the cloud top features a warm center partially surrounded by an arch-shaped region of cold temperatures.

Fig. 6 shows results from offline calculations of the pyroCb's radiative properties after $40 \mathrm{~min}$ simulation time. Figure 6a presents the extinction coefficient resulting from aerosols and hydrometeors in the AVHRR $10.8 \mu \mathrm{m}$ wavelength channel. At this wavelength, scattering is much less significant than absorption, and the extinction is dominated by hydrometeors. The extinction coefficient is highly variable throughout the pyro $\mathrm{Cb}$, with maximum values of $0.25 \mathrm{~m}^{-1}$ in the non-frozen part of the updraft, and more moderate extinction at the cloud top and the anvil. Figure $6 \mathrm{~b}$ depicts the total optical depth relative to the top of the atmosphere. The $\tau=1$ contour can be used to estimate the effective thermal emission level (e.g., Thomas and Stamnes, 1999). Even though the aerosol and hydrometeor extinction is small at the cloud top compared to the pyroCb center, the $\tau=1$ level is located very close to the cloud top, indicating that the temperature structure observed by the satellite radiometer is representative of the conditions at the cloud top. This explains the close agreement between modeled brightness temperature (Fig. 7) and modeled in situ "skin temperature" (Fig. 5c). As discussed in Sect. 2, the observations also support the conclusion that the cloud was optically thick in the thermal IR. Hence the occurrence of the cold U/warm center structure must have been due to dynamic effects at the cloud top rather than radiative effects. The same conclusion was drawn by Wang et al. (2002a,b) for a case of regular deep convection. On the other hand, the mechanism of moisture or cirrus plumes as reported by Setvák et al. (2007) for cases 

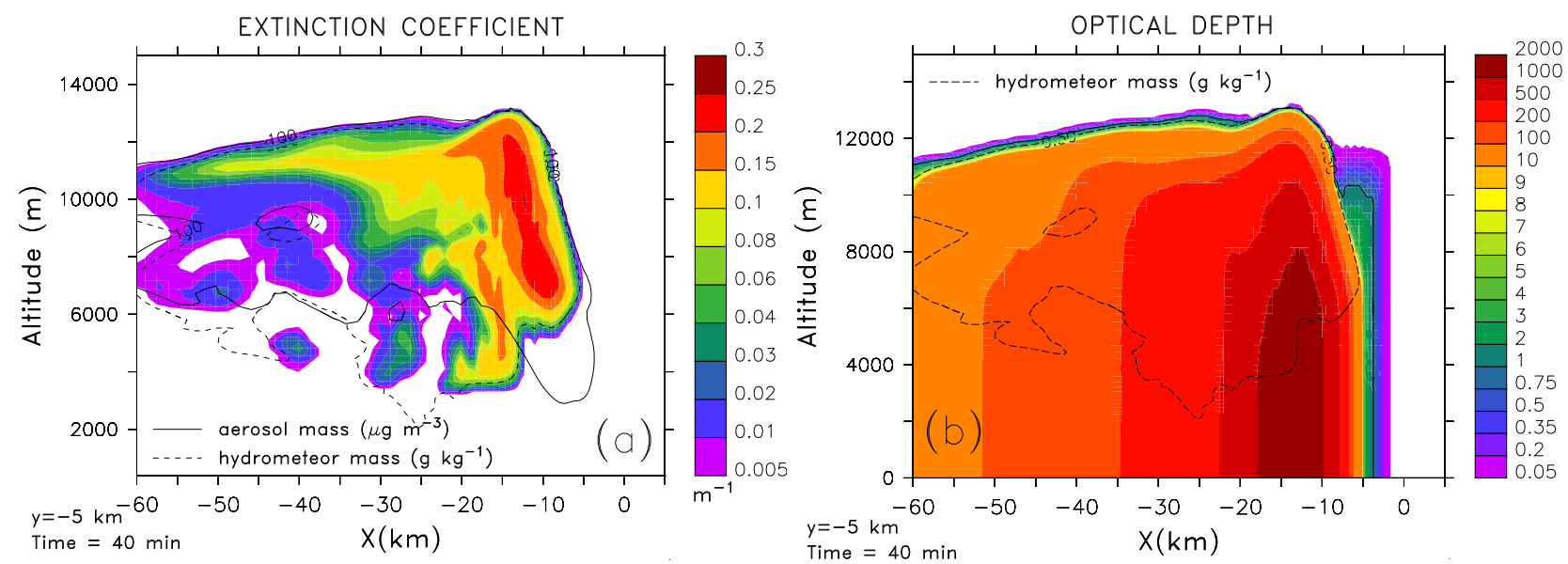

Fig. 6. Results from offline calculation of radiative properties. (a) Extinction due to absorption and scattering by hydrometeors and aerosols at $10.8 \mu \mathrm{m}$. Contours of aerosol mass concentration (solid line) and hydrometeor concentration (dashed line) indicate the extent of the smoke plume and pyroCb. (b) Aerosol and hydrometeor extinction optical depth $\tau$ at $10.8 \mu \mathrm{m}$ from the top of the atmosphere as a function of $z$. Note that the $\tau=1$ contour (solid line), which can be used as an indication of the effective level of emission of the thermal radiation, is situated very close to the cloud top.

of regular deep convective clouds was not relevant for the pyroCb analyzed here.

The simulated cloud top brightness temperature structure (Fig. 7) is in good agreement with the observations. When viewed from above, the warm center is located at the downwind side of the overshooting dome, while the minimum cloud top temperatures are found on the upwind side of the overshoot. For most of the anvil, brightness temperatures are in the -56 to $-59^{\circ} \mathrm{C}$ range, roughly in equilibrium with the tropopause temperature level at this altitude. These brightness temperatures are slightly warmer, by $2-3 \mathrm{~K}$, than in the observations, but are consistent with the uncertainty in the background temperature profile and the anvil altitude, which might have been slightly underestimated by our ATHAM simulations. The maximum cloud top brightness temperature in the warm center is $-48^{\circ} \mathrm{C}$, substantially warmer than the $-58^{\circ} \mathrm{C}$ of the ambient air at this altitude. On the other hand, the minimum brightness temperatures in the cold $\mathrm{U}$ region are close to $-65^{\circ} \mathrm{C}$, about $5^{\circ} \mathrm{C}$ colder than the tropopause cold point. The difference of $17^{\circ} \mathrm{C}$ between the simulated maximum and minimum cloud top temperatures is in good agreement with the AVHRR brightness temperature field, where a difference of $15^{\circ} \mathrm{C}$ between the warm center and the cold U was recorded (see Sect. 2 and Fig. 1b).

\subsection{Gravity wave formation}

Vertical cross-sections through the pyroCb reveal the physical reason for the observed cloud top temperature structure. Figures $8 \mathrm{a}$ and $\mathrm{b}$ depict the temperature anomaly, i.e., the difference between in-situ temperature within the pyrocloud and the background temperature at the correspond-

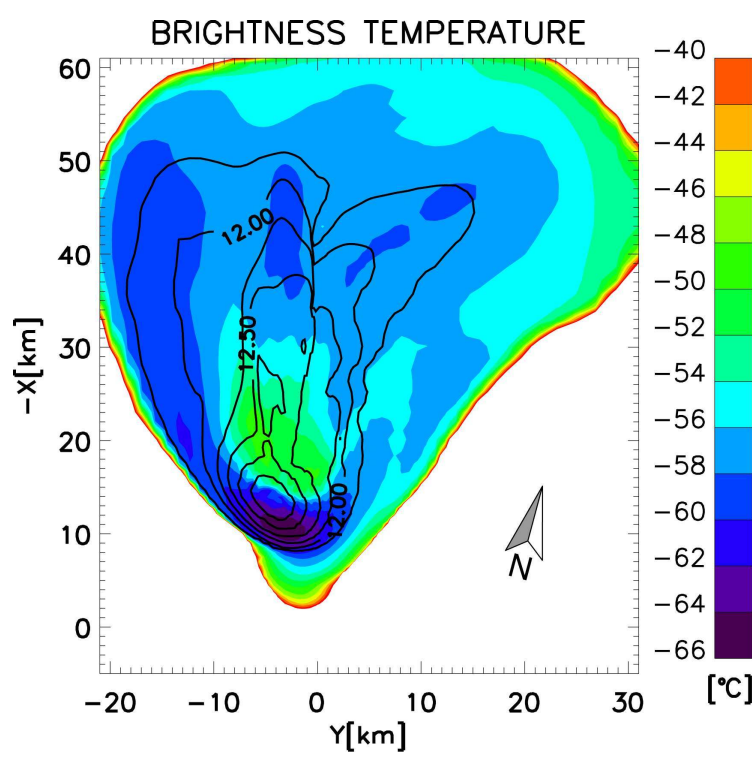

Fig. 7. Brightness temperatures derived from upwelling radiance simulated for the $10.8 \mu \mathrm{m}$ wavelength band. The contour lines indicate the altitude in $\mathrm{km}$ of the $100 \mu \mathrm{g} \mathrm{m}^{-3}$ isosurface of the aerosol mass concentration.

ing altitude level on the vertical plane parallel to the fire front at $y=-5 \mathrm{~km}$. They show a distinct bipolar temperature structure, featuring a strong negative temperature anomaly within the pyroCb's overshooting dome, accompanied by a strong positive temperature anomaly above and downwind (Fig. 8b). A similar bipolar structure is also found in the pressure anomaly and vertical wind fields, indicating a stationary gravity wave induced by the overshoot: The cold overshoot- 

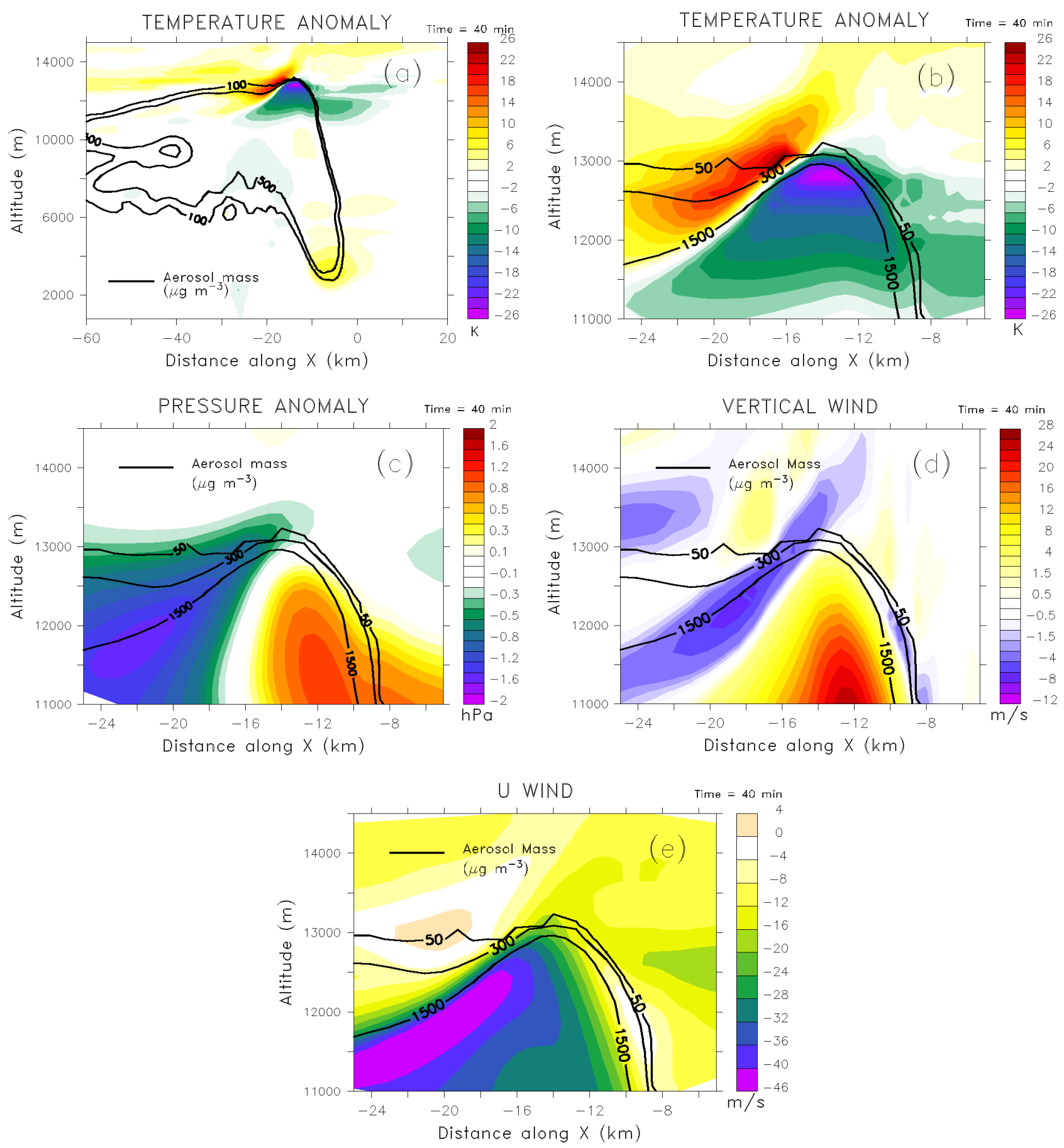

Fig. 8. Vertical cross-sections of (a, b) temperature anomaly, (c) pressure anomaly, (d) vertical wind field, and (e) $u$-component of the horizontal wind at $y=-5 \mathrm{~km}$. Solid black lines indicate isolines of aerosol concentration. Temperature and pressure anomalies are defined as the difference with respect to the background temperature and pressure profiles. The distinct bipolar structure is a clear indication of gravity wave activity.

ing air masses are negatively buoyant and tend to sink as they are advected downwind, thereby creating a negative pressure anomaly on the downwind side of the overshoot (Fig. 8c). In turn, this negative pressure anomaly induces downward motion of air masses from above the cloud top (Fig. 8d). The convection and the overshoot also induce a strong signature in the horizontal wind field (Fig. 8e). The convective outflow into the anvil results in peak wind speeds of about 

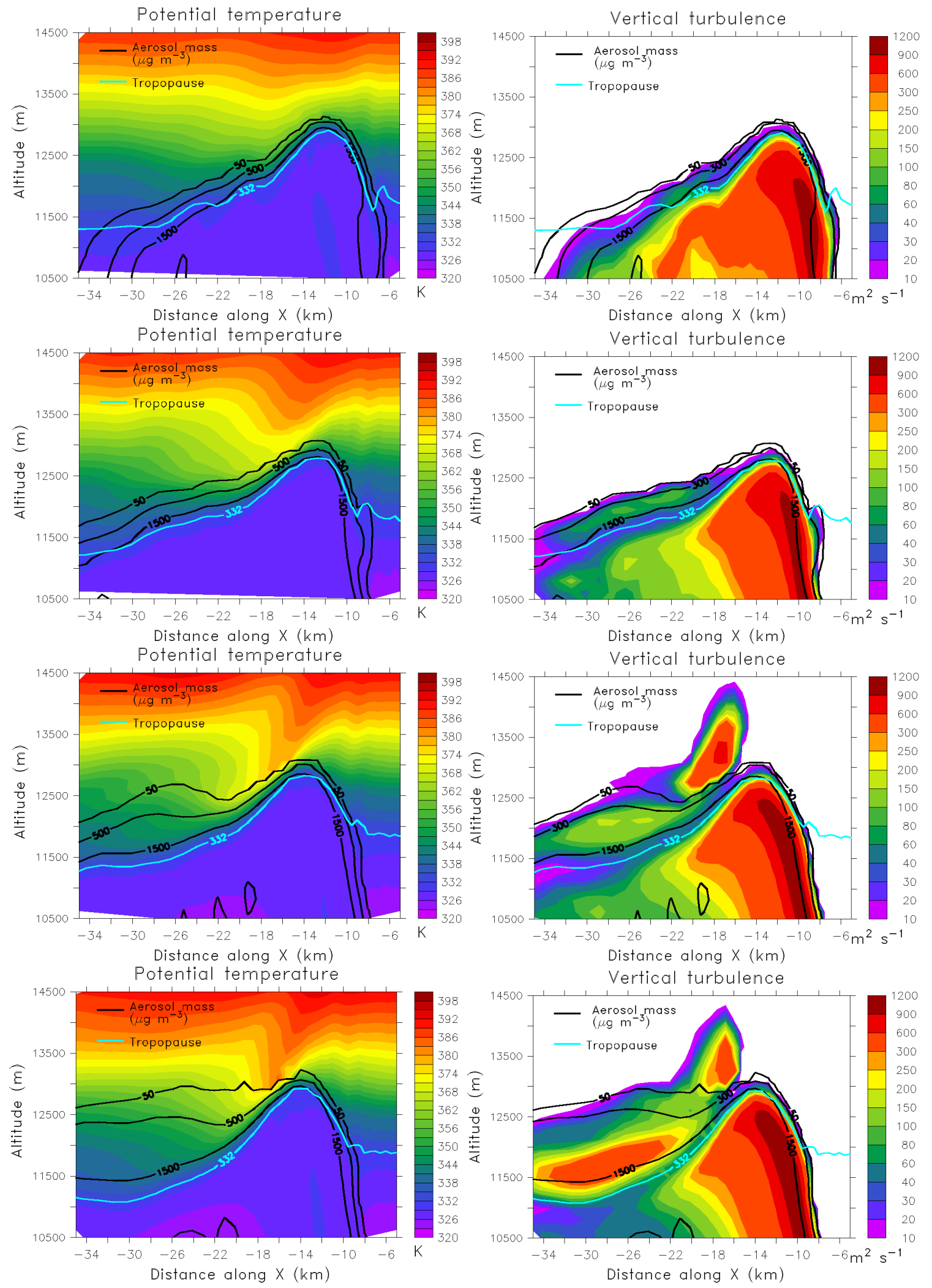

Fig. 9. Vertical cross sections of potential temperature (left column) and vertical turbulent exchange coefficient (right column) for four different points in time. Due to the anisotropic treatment of turbulence in ATHAM (Herzog et al., 2003), the vertical turbulent exchange coefficient $K_{\mathrm{ver}}$ is related to the horizontal turbulent exchange coefficient $K_{\text {hor }}$ as $K_{\mathrm{ver}}=\frac{1}{\sqrt{2}} K_{\text {hor }}$. 
$45 \mathrm{~m} \mathrm{~s}^{-1}$ in the upper part of the cloud at about $12 \mathrm{~km}$ altitude. By contrast, since the overshoot presents an obstacle to the background flow, horizontal velocities of the air masses at the cloud top on the downwind side of the overshoot are close to zero. This pattern results in strong vertical shear of the horizontal wind at the cloud top and generation of turbulence.

Due to adiabatic heating, the downward motion gives rise to the strong positive temperature anomaly above and downwind of the overshooting dome. The gravity wave shows up prominently as a strong perturbation in the potential temperature field (Fig. 9g). The air masses in the warm area right above the cloud top feature $\theta$-values of up to $380 \mathrm{~K}$, indicating that these air masses originate from an altitude level of $13600 \mathrm{~m}$, having descended as much as $600 \mathrm{~m}$.

\subsection{Cross-isentrope transport due to small-scale mixing}

The gravity wave induced by the overshooting cloud top enhances the cross-isentrope transport of smoke laden air into the lower stratosphere in two ways. First, the close proximity of the pyroCb's overshooting dome, with its strong negative temperature anomaly, to a region of air masses with stratospheric origin and positive temperature anomaly above and downwind of the dome results in very large gradients of potential temperature and trace gas concentration directly atop of the overshooting dome. Second, gravity wave breaking generates additional turbulence, thereby greatly enhancing the mixing efficiency.

Figure 9 depicts vertical cross sections through the fields of potential temperature (a, c, e, g) and of the vertical turbulent exchange coefficient, as simulated by ATHAM's turbulence scheme $(b, d, f, h)$ for four points in time. During the first $20 \mathrm{~min}$ of the development of the pyroCb, the air masses in the cloud are highly turbulent, with maximum values of the vertical turbulent exchange coefficient of up to $1500 \mathrm{~m}^{2} \mathrm{~s}^{-1}$ at the center of the updraft. The strong gradient of potential temperature above the overshooting dome, i.e., a very stable stratification, acts as a sink for TKE. Therefore, the turbulent exchange coefficient strongly decreases at the cloud top.

After about $30 \mathrm{~min}$ of simulation time, the gravity wave becomes unstable due to the vertical wind shear at the tropopause level. Downwind of the overshooting dome, air masses with high potential temperature are transported below potentially colder air masses, resulting in gravity wave breaking (Fig. 9e). Such gravity wave breaking is a highly efficient mechanism for the generation of turbulence (Fig. 9f). Moreover, the strong vertical wind shear (cf. Fig. 8e) at the cloud top downwind of the overshoot is an important source of turbulence. It gives rise to a second maximum of vertical turbulence that ranges from about $x=-20 \mathrm{~km}$ to $x=-30 \mathrm{~km}$ along the cloud top. It is evident from the potential temperature and turbulence fields after 40 min (Figs. 9g, h) that the advection of gravity-wave and wind-shear generated turbulence along the cloud top results in very efficient mixing of smoke laden air masses of the pyro-cloud with potentially warm air masses of stratospheric origin.

As discussed in Sect. 4.2, such cloud top mixing of potentially warm stratospheric air with smoke and hydrometeor enriched pyroCb air gives rise to the warm center structure as observed in the thermal satellite imagery. This establishes a direct link between the thermal structure and TST above deep convection, hence the cold U/warm center feature as derived from satellite could serve as an indicator for the occurrence of TST above deep convection.

\subsection{Troposphere-to-stratosphere transport}

In order to assess troposphere-to-stratosphere transport (TST) of smoke tracers, it is instructive to consider vertical tracer distributions both as a function of altitude, and as a function of potential temperature. The temporal evolution of such vertical aerosol distributions is given in Fig. 10.

The most notable feature of this analysis is the fact that the maximum penetration altitude is already reached after $20 \mathrm{~min}$, whereas the aerosol distribution as a function of potential temperature continues to progress to higher values as the simulation advances in time.

As shown in Fig. 10a, the maximum penetration height is approximately $13000 \mathrm{~m}$. The main outflow height of the smoke is at $10500 \mathrm{~m}$, giving rise to a peak in the vertical aerosol mass distribution at this level. Over the course of the simulation, due to the continuing convective vertical transport of smoke, increasing amounts of aerosol mass become injected and the layers above $7000 \mathrm{~m}$ become increasingly enriched in aerosol mass. The maximum penetration height, however, remains almost unchanged once the $13000 \mathrm{~m}$ level is reached after about $20 \mathrm{~min}$, i.e., the strong inversion in the lower stratosphere inhibits further vertical ascent of the air parcels in the overshoot to higher altitude levels.

In terms of TST, however, the aerosol distribution as a function of potential temperature $\theta$ is more meaningful (Fig. 10b). In order to mask out the high temperatures directly above the fire, only smoke parcels above an altitude of $5000 \mathrm{~m}$ were considered for the analysis presented here. At this level, the sensible heat from the fire is sufficiently diluted, so that the high potential temperature tail of the aerosol distribution represents smoke located in the tropopause region only. In contrast to the maximum penetration altitudes, the maximum $\theta$-values reached by the aerosol plume continue to rise to higher levels: The aerosol density exceeds $1000 \mathrm{~kg} \mathrm{~K}^{-1}$ up to a potential temperature level of $342 \mathrm{~K}$ after $20 \mathrm{~min}, 350 \mathrm{~K}$ after $30 \mathrm{~min}, 354 \mathrm{~K}$ after $40 \mathrm{~min}$ and $359 \mathrm{~K}$ after $50 \mathrm{~min}$.

The continuous increase in maximum potential temperature without an increase in maximum altitude strongly supports the finding that, in addition to convective advection, other driving forces are responsible for the cross-tropopause transport at the cloud top. We can assess the relative impor- 

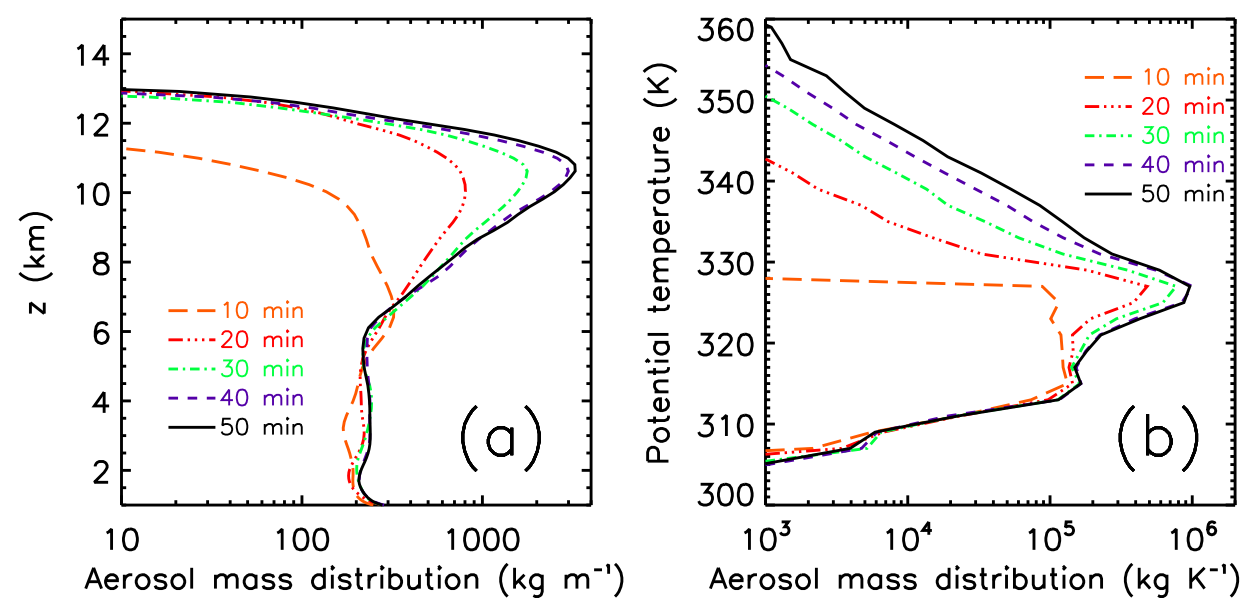

Fig. 10. Temporal evolution of the vertical distributions of aerosol mass as a function of (a) altitude and (b) potential temperature.

tance of turbulent mixing by considering the energy balance of an individual air parcel.

The difference in potential temperature between the boundary layer and the lower stratosphere is typically of the order of several tens of $\mathrm{K}$. According to traditional parcel theory, the most important heat source in an air mass ascending within a convection column is the latent heat from condensing water. The equivalent potential temperature incorporates the amount of latent heating that would be added if all the water vapor contained in the air parcel was condensed. In the case of the Chisholm fire, equivalent potential temperature was almost constant throughout the lower troposphere. If a modified equivalent potential temperature definition that also takes into account the latent heat of freezing is used, values are 324-326 K from the boundary layer to an altitude of about $7.5 \mathrm{~km}$, with the exception of a few outliers with colder equivalent potential temperatures. The equivalent potential temperature level of the tropopause, by contrast, was $332 \mathrm{~K}$ - hence latent heating alone would not have been sufficient to lift air masses into the lower stratosphere. For pyroCbs, of course, heating from the fire is an important additional contributor to the internal energy of air parcels. As reported in Trentmann et al. (2006), we estimate that the fire heating contributed about $6 \mathrm{~K}$ to the temperature of air parcels at the anvil level of the Chisholm pyroCb. The combined effect of latent heating and fire heating can thus yield potential temperatures of $330-332 \mathrm{~K}$.

This is in good agreement with the main outflow level of the pyroCb. On the other hand, as shown by Fig. 10, a substantial fraction of the aerosol mass ends up at much higher potential temperature levels. Neglecting radiative heating, which is not significant on the short time scales considered here, any aerosol mass above the $\theta=332 \mathrm{~K}$ tropopause level must be the result of mixing with stratospheric air characterized by large values of potential temperature. We can thus conclude that the small-scale mixing processes, most impor- tantly those induced by gravity wave breaking at the cloud top, increased the stratospheric penetration of the pyroCb smoke by as much as to $20-30 \mathrm{~K}$.

\section{Summary and conclusions}

We investigated the cloud top of an intense pyroCb and provide an explanation for the occurrence of the peculiar cold U/warm center cloud top temperature structure that has also been observed for other cases of severe thunderstorm convection. A close link between the cold U/warm center feature and TST induced by small-scale mixing processes at the cloud top was established.

The model results presented here show that the cold U/warm center cloud top temperature pattern observed from satellite radiometry can be closely reproduced with the cloud resolving model ATHAM. Analysis of the simulated fields of potential temperature and other prognostic variables of the model demonstrates that this feature is due to dynamic processes at the cloud top: The pyroCb's overshooting dome induces a stationary gravity wave, which strongly enhances mixing of smoke laden air masses of the pyroCb with stratospheric air masses characterized by high potential temperatures. The gravity wave generates large gradients of potential temperature and tracer concentration. Turbulence is produced by gravity wave breaking and vertical wind shear forming at the cloud top downwind of the overshoot. These two important mechanisms of turbulence generation are consistent with the two regions of enhanced turbulence identified for a case of regular convection by Lane et al. (2003). The turbulence results in efficient mixing across isentropes. While convective advection, latent heating and sensible heating from the fire alone can explain only the transport of air masses to tropopause levels of about 330-332 K, the smallscale mixing processes presented in this paper are of key im- 
portance for the injection of a small but significant fraction of smoke to lower stratospheric potential temperature levels of up to $360 \mathrm{~K}$. Thus, small-scale mixing increased the stratospheric penetration of the smoke by almost $30 \mathrm{~K}$.

While gravity wave induced mixing and turbulence generation at the cloud top fully explain the observations for the case studied here, it is important to point out that there are other processes that can contribute to the formation and overall appearance of satellite IR features for other convective clouds. Cirrus plumes above the anvil level as described by Setvák et al. (2007), for instance, may have a strong influence on the shape of cold U/warm center structures. Our explanation for the formation of the cold U/warm center structure based on small-scale mixing processes is in good agreement with the thunderstorm cloud top dynamics presented by Schlesinger (1984) and Adler and Mack (1986). The finding that the observed structure was due to dynamic rather than radiative effects supports results from studies of regular convection that showed a dominant role of dynamic effects in forming cold U/warm center structures (Wang et al., 2002a,b).

The importance of gravity wave formation and breaking for TST of pyroCb smoke found here is very similar to the role of gravity waves in transporting water vapor to the lower stratosphere by mid-latitude convection as described by Wang $(2003,2007)$. The close connection between the thermal structure of the cloud top as observed from satellite and TST, as demonstrated in this study, opens up the possibility of assessing the occurrence of TST induced by deep convection using IR satellite observations.

PyroCb induced smoke injection is an important source of trace gases and aerosols in the upper troposphere and lower stratosphere. Modeling studies are an important tool to advance our understanding of the relevant mechanisms. The Chisholm fire case study, presented here and in Luderer et al. (2006) and Trentmann et al. (2006), suggests that the principal ingredients for direct smoke injection by pyroCbs are 1) strong fire forcing through heat release, 2) favorable meteorological conditions, with, most importantly, sufficient moisture in the lower and mid-troposphere, and 3) small-scale mixing processes at the cloud top.

More studies are needed to further improve our understanding of the causes and effects of UT/LS aerosol plumes originating from forest fires. Moreover, more convection scale modeling studies also for other cases and geographical regions would be desirable. Regional simulations also considering radiative effects for longer timescales and larger spatial scales would enhance the understanding of the further development of lower stratospheric aerosol plumes induced by pyroCbs. Finally, global chemistry climate models should be used to assess the effect of forest fire smoke on radiative balance and lower stratospheric chemistry.
Acknowledgements. We would like to thank H. Wernli, D. Rosenfeld, R. Servranckx and S. Eto for stimulating discussions. We would also like to thank T. Trautmann for his support with the radiative transfer calculations. The helpful comments provided by P. Wang and an anonymous reviewer are greatly appreciated. G. Luderer was supported by an International Max Planck Research School fellowship. J. Trentmann was supported by the Helmholtz Association within the Virtual Institute COSI TRACKS. This work was also funded by the Max Planck Society.

Edited by: T. Garrett

\section{References}

Adler, R. F. and Mack, R. A.: Thunderstorm Cloud Top Dynamics as Inferred from Satellite Observations and a Cloud Top Parcel Model, J. Atmos. Sci., 43, 1945-1960, 1986.

Anderson, G. P., Clough, S. A., Kneizys, F. X., Chetwynd, J. H., and Shettle, E. P.: AFGL atmospheric constituent profiles (0-120 km), Tech. Rep. AFGL-TR-86-0110, Air Force Geophys. Lab., Hanscom Air Force Base, Mass., 1986.

Andreae, M. O. and Merlet, P.: Emission of trace gases and aerosols from biomass burning, Global Biogeochem. Cy., 15, 955-966, 2001.

ASRD: Final Documentation Report - Chisholm Fire (LWF-063), Forest Protection Division, ISBN 0-7785-1841-8, Tech. rep., Alberta Sustainable Resource Development, 2001.

Fischer, H., de Reus, M., Traub, M., Williams, J., Lelieveld, J., de Gouw, J., Warneke, C., Schlager, H., Minikin, A., Scheele, R., and Siegmund, P.: Deep convective injection of boundary layer air into the lowermost stratosphere at midlatitudes, Atmos. Chem. Phys., 3, 739-745, 2003,

http://www.atmos-chem-phys.net/3/739/2003/.

Fromm, M., Bevilacqua, R., Servranckx, R., Rosen, J., Thayler, J., Herman, J., and Larko, D.: Pyro-cumulonimbus injection of smoke into the stratosphere: Observations and impact of a super blowup in northwestern Canada on 3-4 August 1998, J. Geophys. Res., 110, D08205, doi:10.1029/2004JD005350, 2005.

Fromm, M. D. and Servranckx, R.: Transport of forest fire smoke above the tropopause by supercell convection, Geophys. Res. Lett., 30, 1542, doi:10.1029/2002GL016820, 2003.

$\mathrm{Fu}$, Q. and Liou, K. N.: Parameterization of the radiative properties of cirrus clouds, J. Atmos. Sci., 50, 2008-2025, 1993.

Graf, H.-F., Herzog, M., Oberhuber, J. M., and Textor, C.: The effect of environmental conditions on volcanic plume rise, J. Geophys. Res., 104, 24 309-24 320, 1999.

Hanisco, T. F., Moyer, E. J., Weinstock, E. M., St. Clair, J. M., Sayres, D. S., Smith, J. B., Lockwood, R., Anderson, J. G., Dessler, A. E., Keutsch, F. N., Spackman, J. R., Read, W. G., and Bui, T. P.: Observations of deep convective influence on stratospheric water vapor and its isotopic composition, Geophys. Res. Lett., 34, L04814, doi:10.1029/2006GL027899, 2007.

Herzog, M., Graf, H.-F., Textor, C., and Oberhuber, J. M.: The effect of phase changes of water on the development of volcanic plumes, J. Volcanol. Geotherm. Res, 87, 55-74, 1998.

Herzog, M., Oberhuber, J. M., and Graf, H.-F.: A prognostic turbulence scheme for the nonhydrostatic plume model ATHAM, J. Atmos. Sci., 60, 2783-2796, 2003. 
Heymsfield, G. M. and Blackmer, Jr., R. H.: Satellite-Observed Characteristics of Midwest Severe Thunderstorm Anvils, Mon. Wea. Rev., 116, 2200-2224, 1988.

Heymsfield, G. M., Sezejwach, G., Schotz, S., and Blackmer, Jr, R. H.: Upper level structure of Oklahoma tornadic stroms on 2 May 1979. II: Proposed explanation of "V" pattern and internal warm region in infrared observation, J. Atmos. Sci., 40, 17561767, 1983.

Holton, J. R., Haynes, P. H., McIntyre, M. E., Douglass, A. R., Rood, R. B., and Pfister, L.: Stratosphere-Troposphere Exchange, Rev. Geophys., 33, 403-439, 1995.

Hungershöfer, K.: Optical properties of aerosol particles and radiative transfer in connection with biomass burning, Ph.D. thesis, Institute for Meteorology, University of Leipzig, 2007.

Inoue, T.: A cloud type classification with NOAA 7 split-window measurements, J. Geophys. Res., 92, 3991-4000, 1987.

Lane, T. P. and Sharman, R. D.: Gravity wave breaking, secondary wave generation, and mixing above deep convection in a threedimensional cloud model, Geophys. Res. Lett., 33, L23813, doi: 10.1029/2006GL027988, 2006.

Lane, T. P., Sharman, R. D., Clark, T. L., and Hsu, H.-M.: An Investigation of Turbulence Generation Mechanisms above Deep Convection, J. Atmos. Sci., 60, 1297-1321, 2003.

Levizzani, V. and Setvák, M.: Multispectral, High-Resolution Satellite Observations of Plumes on Top of Convective Storms, J. Atmos. Sci., 53, 361-369, 1996.

Luderer, G., Trentmann, J., Winterrath, T., Textor, C., Herzog, M., and Andreae, M. O.: Modeling of biomass smoke injection into the lower stratosphere by a large forest fire (Part II): Sensitivity studies, Atmos. Chem. Phys., 6, 5261-5277, 2006, http://www.atmos-chem-phys.net/6/5261/2006/.

Mullendore, G. L., Durran, D. R., and Holton, J. R.: Crosstropopause tracer transport in midlatitude convection, J. Geophys. Res., 110, D06113, doi:10.1029/2004JD005059, 2005.

Oberhuber, J. M., Herzog, M., Graf, H.-F., and Schwanke, K.: Volcanic plume simulation on large scales, J. Volcanol. Geotherm. Res, 87, 29-53, 1998.

Pittman, J. V., Weinstock, E. M., Oglesby, R. J., Sayres, D. S., Smith, J. B., Anderson, J. G., Cooper, O. R., Wofsy, S. C., Xueref, I., Gerbig, C., Daube, B. C., Richard, E. C., Ridley, B. A., Weinheimer, A. J., Loewenstein, M., Jost, H.-J., Lopez, J. P., Mahoney, M. J., Thompson, T. L., Hargrove, W. W., and Hoffman, F. M.: Transport in the subtropical lowermost stratosphere during the Cirrus Regional Study of Tropical Anvils and Cirrus Layers-Florida Area Cirrus Experiment, J. Geophys. Res., 112, D08304, doi:10.1029/2006JD007851, 2007.

Ray, E. A., Rosenlof, K. H., Richard, E. C., Hudson, P. K., Cziczo, D. J., Loewenstein, M., Jost, H.-J., Lopez, J., Ridley, B., Weinheimer, A., Montzka, D., Knapp, D., Wofsy, S. C., Daube, B. C., Gerbig, C., Xueref, I., and Herman, R. L.: Evidence of the effect of summertime midlatitude convection on the subtropical lower stratosphere from CRYSTAL-FACE tracer measurements, J. Geophys. Res., 109, D18304, doi:10.1029/2004JD004655, 2004.

Reid, J. S., Koppmann, R., Eck, T. F., and Eleuterio, D. P.: A review of biomass burning emissions part II: intensive physical properties of biomass burning particles, Atmos. Chem. Phys., 5, 799825,2005 ,

http://www.atmos-chem-phys.net/5/799/2005/.
Rosenfeld, D., Fromm, M., Trentmann, J., Luderer, G., Andreae, M. O., and Servranckx, R.: The Chisholm firestorm: observed microstructure, precipitation and lightning activity of a pyrocumulonimbus, Atmos. Chem. Phys., 7, 645-659, 2007, http://www.atmos-chem-phys.net/7/645/2007/.

Schlesinger, R. E.: Mature Thunderstorm Cloud-Top Structure and Dynamics: A Three-Dimensional Numerical Simulation Study., J. Atmos. Sci., 41, 1551-1570, 1984.

Setvák, M., Rabin, R. M., and Wang, P. K.: Contribution of the MODIS instrument to observations of deep convective storms and stratospheric moisture detection in GOES and MSG imagery, Atmos. Res., 83, 505-518, 2007.

Textor, C., Graf, H.-F., Herzog, M., and Oberhuber, J. M.: Injection of gases into the stratosphere by explosive volcanic eruptions, J. Geophys. Res., 108, 4606, doi:10.1029/2002JD002987, 2003.

Textor, C., Graf, H. F., Herzog, M., Oberhuber, J. M., Rose, W. I., and Ernst, G. G. J.: Volcanic particle aggregation in explosive eruption columns. Part I: Parameterization of the microphysics of hydrometeors and ash, J. Volcanol. Geotherm. Res., 150, 359377, 2006a.

Textor, C., Graf, H. F., Herzog, M., Oberhuber, J. M., Rose, W. I., and Ernst, G. G. J.: Volcanic particle aggregation in explosive eruption columns. Part II: Numerical experiments, J. Volcanol. Geotherm. Res., 150, 378-394, 2006b.

Thomas, G. E. and Stamnes, K.: Radiative transfer in the atmosphere and ocean, Cambridge University Press, Cambridge, 517 pp., 1999.

Trentmann, J., Andreae, M. O., Graf, H.-F., Hobbs, P. V., Ottmar, R. D., and Trautmann, T.: Simulation of a biomass-burning plume: Comparison of model results with observations, J. Geophys. Res., 107, 4013, doi:10.1029/2001JD000410, 2002.

Trentmann, J., Luderer, G., Winterrath, T., Fromm, M., Servranckx, R., Textor, C., Herzog, M., and Andreae, M. O.: Modeling of biomass smoke injection into the lower stratosphere by a large forest fire (Part I): Reference study, Atmos. Chem. Phys., 6, 5247-5260, 2006, http://www.atmos-chem-phys.net/6/5247/2006/.

Wang, P. K.: Moisture plumes above thunderstorm anvils and their contributions cross-tropopause transport of water vapor in midlatitudes, J. Geophys. Res., 108, 4194, doi:10.1029/ 2002JD002581, 2003.

Wang, P. K.: The thermodynamic structure atop a penetrating convective thunderstorm, Atmos. Res., 83, 254-262, 2007.

Wang, P. K., Lin, H. M., Natali, S., Bachmeier, S., and Rabin, R.: Cloud model interpretation of mechanisms responsible for the satellite-observed enhanced $\mathrm{V}$ and other features atop some Midwest severe thunderstorms, Preprints of the 11th AMS Conference on Cloud Physics, Ogden, Utah, USA, Paper 1.2, 2002a.

Wang, P. K., Lin, H. M., Natali, S., Bachmeier, S., and Rabin, R.: Enhanced V's and other thunderstorm features, B. Am. Meteorol. Soc., 83, 843-844, 2002 b. 